\title{
Keterlibatan Perempuan dalam Usaha Pertanian di Desa Goarie, Kecamatan Marioriwawo, Kabupaten Soppeng
}

\author{
Sulviati $^{1}$, Maddatuang ${ }^{2}$, Alief Saputro ${ }^{3}$,Muhamad Ihsan Azhim ${ }^{4}$ \\ ${ }^{123}$ Pendidikan Geografi Universitas Negeri Makassar \\ ${ }^{4}$ Dinas Pendidikan Provinsi Sulawesi Selatan
}

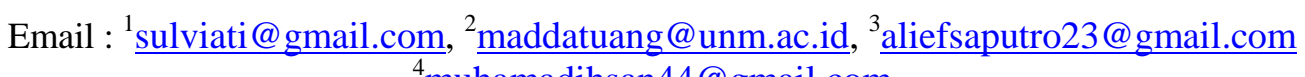
${ }^{4}$ muhamadihsan44@gmail.com

(Received: Agustus 2019; Reviewed: Agustus 2019; Accepted: September 2019; Published: September 2019)

\section{ABSTRACT}

The view that the role of men is the productive role in the public sector and the role of women is a reproductive role in the domestic sector. This study aims to identify and analyze the participation of women in farm management in Goarie Village, Marioriwawo Subdistrict, Soppeng Regency. The research uses the qualitative approach and a case study research type. Data collection techniques are by in-depth interviews, observation wihout partisipation, literature review, and documentation. Informant determination technique is done by purposive sampling. The informants comprised 5 women or families whose main job are farmers and involve in farming activities with their husbands, and had married for at least 4 years. The data analysis consists of data reduction phase, data presentation, and the conclusion, which then analized using the technique componential analysis. The research results indicated that the women participate in all phases of farm management, ranging from land preparation, seedlings, planting, fertilizing, maintenance, harvesting, post-harvest management, sales, storage of sales proceeds, and utilization of sales proceeds.It is concluded, the women participate in all phases of the farm management, and dominand in the nursey, harvesting, post-harvest proceeds, sales, storage, and utilization of sales proceeds

Keywords: Participation; Women; Farm Enterprises

\begin{abstract}
ABSTRAK
Pandangaan bahwa peran laki-laki adalah peran produktif di sektor publik dan peran perempuan adalah peran reproduktif di sektor domestik. Penelitian ini bertujuan untuk mengetahui dan menganalisis partisipasi perempuan dalam pengelolaan usaha tani di Desa Goarie, Kecamatan Marioriwawo, Kabupaten Soppeng. Penelitian ini menggunakan pendekatan kualitatif dan jenis penelitian studi kasus. Teknik pengumpulan data yaitu dengan wawancara mendalam, observasi tidak turut serta, kajian kepustakaan, dan dokumentasi. Teknik penentuan informan dilakukan dengan cara purposive sampling. Informan dalam penelitian ini adalah 5 orang perempuan atau keluarga yang pekerjaan pokoknya adalah petani dan ikut terlibat dalam kegiatan usaha tani bersama suaminya, serta telah menikah minimal 4 tahun. Teknik analisis data terdiri dari tahap reduksi
\end{abstract}


data, penyajian data, dan penarikan kesimpulan yang selanjutnya dianalisis dengan menggunakan teknik analisis komponensial. Hasil penelitian menunjukkan bahwa perempuan ikut berpartisipasi dalam semua tahap pengelolaan usaha tani, yaitu mulai dari persiapan lahan, pembibitan, penanaman, pemupukan, perawatan, panen, pengolahan pasca panen, penjualan, penyimpanan hasil penjualan, dan pemanfaatan hasil penjualan. Disimpulkan bahwa perempuan berpartisipasi dalam semua tahap pengelolaan usaha tani dan dominan pada tahap pembibitan, panen, pengolahan pasca panen, penjualan, penyimpanan, dan pemanfaatan hasil penjualan.

Kata Kunci: : Partisipasi; Perempuan; Usaha Tani

\section{PENDAHULUAN}

Kantor Menteri Negara Pemberdayaan Perempuan Republik Indonesia dan Women Support Project II/CIDA, 2001 (dalam Nugroho, 2011) menyebutkan bahwa "Istilah 'gender' pertama kali diperkenalkan oleh Robert Stoller (1968) untuk memisahkan pencirian manusia yang didasarkan pada pendefinisian yang bersifat sosial budaya dengan pendefinisian yang berasal dari ciriciri fisik biologis. Dalam ilmu sosial orang yang juga sangat berjasa dalam mengembangkan istilah dan pengertian gender ini adalah Ann Oakley (1972). Sebagaimana Stoller, Oakley mengartikan gender sebagai konstruksi sosial atau atribut yang dikenakan pada manusia yang dibangun oleh kebudayaan manusia " (Nugroho, 2011: 2-3).

"Dalam Women's Studies Encyclopedia dijelaskan bahwa gender adalah suatu konsep kultural yang berupaya membuat perbedaan (distinction) dalam peran, perilaku, mentalitas, dan karakter emosional antara laki-laki dan perempuan yang berkembang dalam masyarakat. Dengan demikian gender merupakan harapan-harapan budaya (cultural expectations for women and men) terhadap laki-laki dan perempuan. Konsep gender secara mendasar berbeda dengan jenis kelamin biologis. Jenis kelamin biologis; lakilaki atau perempuan merupakan faktor yang sifatnya kodrati (pemberian dari Tuhan), sedangkan jalan yang menjadikan seorang memiliki sifat feminitas dan maskulinitas adalah gabungan antara faktor biologis dan interpretasi biologis oleh kultur sosial" (Sulaeman dan Homzah, 2010: 2-3).

Penelitian Hutajulu (2015) yang dimuat pada Jurnal Social Economic of Agriculture menunjukkan bahwa "perempuan disamping sebagai ibu rumah tangga pada keluarga berbasis petani di Desa Rasau Jaya I, juga terlibat cukup banyak dalam mengelola ekonomi pertanian yang dikelola keluarga" (Hutajulu, 2015:89).

Pandangan bahwa peran laki-laki adalah peran produktif di sektor publik untuk mencari nafkah bagi keluarganya dan peran perempuan adalah peran reproduktif di sektor domestik untuk mengurus rumah tangga. Kondisi ini berbeda dengan keluarga petani di Desa Goarie, Kecamatan Marioriwawo, Kabupaten Soppeng. Pengelolaan usaha tani tidak hanya dikerjakan oleh laki-laki tetapi perempuan juga ikut terlibat. Oleh karena itu, penelitian ini bertujuan untuk mengetahui dan menganalisis partisipasi perempuan dalam pengelolaan usaha tani di Desa Goarie, Kecamatan Marioriwawo, Kabupaten Soppeng.

\section{METODE}

\section{Lokasi dan Rancangan Penelitian}

Penelitian ini dilaksanakan di Desa Goarie, Kecamatan Marioriwawo, Kabupaten Soppeng.. Pendekatan yang digunakan adalah kualitatif dan jenis penelitian studi kasus.

\section{Informan Penelitian}

Informan dalam penelitian ini ditentukan secara sengaja atau cara purposive sampling. Informan dalam penelitian ini adalah 5 orang perempuan atau keluarga yang memiliki kriteria yaitu telah menikah, pekerjaan utamanya adalah petani, dan ikut terlibat dalam kegiatan usaha tani bersama suaminya, serta telah menikah minimal 4 tahun. Sugiyono (2014) menyatakan bahwa 
"penentuan sampel dalam penelitian kualitatif tidak didasarkan perhitungan statistik. Sampel yang dipilih berfungsi untuk mendapatkan informasi yang maksimum, bukan untuk digeneralisasikan" (Sugiyono, 2014: 302).

\section{Metode Pengumpulan Data}

Teknik pengumpulan data dalam penelitian ini yaitu dengan wawancara mendalam, observasi tidak turut serta, kajian kepustakaan, dan dokumentasi.

\section{Analisis Data}

Seluruh hasil data penelitian yang telah dikumpulkan atau diperoleh dalam penelitian ini dianalisis secara kualitatif dengan cara menggambarkan masalah secara jelas dan mendalam yang kemudian hasil dari penggambaran masalah diinterpretasikan sesuai dengan hasil penelitian yang dilakukan. Secara ringkas, analisa data dilakukan melalui tahapan yaitu tahap reduksi data, tahap penyajian data, dan tahap panarikan kesimpulan. Data yang telah diperoleh setelah diolah selanjutnya dianalisis dengan menggunakan analisis komponensial. Sementara untuk menjamin validitas data, maka penulis menggunakan teknik triangulasi sumber.

\section{HASIL DAN PEMBAHASAN}

\section{Hasil}

\section{Partisipasi Perempuan dalam Usaha Tani}

Penelitian ini menunjukkan bahwa perempuan di Desa Goarie, Kecamatan Marioriwawo, Kabupaten Soppeng ikut berpartisipasi dalam pengelolaan usaha tani. Semua tahap pengelolaan usaha tani perempuan ikut berpartisipasi. Tahap tersebut adalah persiapan lahan, pembibitan, penanaman, pemupukan, perawatan, panen, pengolahan pasca panen, penjualan, penyimpanan, dan memanfaatan hasil penjualan.

Pada persiapan lahan, perempuan terlibat dalam membawa bekal, mencangkul, dan memperbaiki pematang sawah. Kegiatan tersebut mereka lakukan bersama-sama dengan suaminya. Pada tahap pembibitan, perempuan banyak terlibat membeli bibit, merendam bibit, menyemai, dan mencabut bibit (bine).

Tahap penanaman, perempuan terlibat membantu membawa bibit (bine) ke sawah, menebar bibit yang telah dibawa agar mudah ditanam, dan kadang-kadang membantu menanam. Pada tahap pemupukan, perempuan ikut terlibat membeli pupuk, membawa pupuk ke sawah, dan ikut melakukan pemupukan. Pada tahap perawatan, perempuan membeli racun, kadang-kadang ikut menyemprot hama dan gulma, membersihkan rumput yang tumbuh, dan mengontrol air yang mengalir ke sawah.

Tahap panen, perempuan membawa bekal ke sawah, memotong padi, membawa padi yang telah dipotong (disangki) ke tempat penampungan untuk dirontok atau pemisahan antara gabah dan jerami, pada saat padi dirontok biasanya perempuan mempersiapkan karung penampungan, memanggil orang untuk membantu pada saat panen, memberikan upah berupa gabah kepada orang yang membantu pada saat mencabut bibit (mangngubbu') dan memotong padi (massangki), dan ikut membawa atau mengurus padi hingga sampai ke rumah. Tahap pasca panen, perempuan menjemur atau mengeringkan padi kemudian menyimpannya.

Tahap penjualan, perempuan yang menjual hasil panen baik dalam bentuk gabah atau beras. Tahap penyimpanan, perempuan yang menyimpan hasil penjualan. Tahap pemanfaatan, perempuan yang membelanjakan untuk kebutuhan keluarga.

Wawancara dengan informan menunjukkan bahwa partisipasi mereka dalam kegiatan usaha tani mendapat dukungan dari suaminya karena dalam kegiatan usaha tani memang harus saling membantu dan mendukung. Kegiatan lain yang perempuan lakukan saat tidak melakukan kegiatan usaha tani adalah mengurus kebun dan ternak.

\section{Pembahasan}

Hasil penelitian yang dilakukan oleh penulis memperlihatkan bahwa perempuan ikut serta berpartisipasi dalam pengelolaan usaha tani. Perempuan terlibat dalam kegiatan persiapan lahan, pembibitan, penanaman, pemupukan, perawatan, panen, pasca panen, penjualan, penyimpanan, dan pemanfaatan atau pembelanjaan. Berdasarkan hasil wawancara dengan informan bahwa hal tersebut mereka lakukan karena sebagai petani harus saling mendukung dan membantu jalan 
menjalankan kegiatan usaha tani.

Tahap pengelolaan usaha tani tersebut, kualitas partisipasi perempuan yang menonjol adalah pada tahap pembibitan, panen, pasca panen, penjualan, penyimpanan hasil penjualan, dan pemanfaatan hasil penjualan/membelanjakan hasil penjualan. Perempuan ikut terlibat bersama suaminya dalam kegiatan usaha tani bukan untuk saling bersaing satu dengan yang lain tetapi untuk saling membantu dan bekerjasama dalam menjalankan pekerjaan atas dasar saling menghargai. Kondisi tersebut berbeda dengan pandangan Talcot Parsons bahwa "pengaturan yang jelas bahwa wanita harus bekerja di dalam rumah tangga, maka ditiadakan kemungkinan terjadinya persaingan antara suami dan istri” (Parsons dalam Budiman,1981: 18).

Partisipasi yang dilakukan oleh perempuan atau istri tersebut tidak membuat mereka meninggalkan tugas atau pekerjaan mereka di rumah. Hasil wawancara dengan informan menunjukkan bahwa suami mendukung keterlibatan istri dalam usaha tani. Mereka mengakui peran penting perempuan dalam usaha tani. Hal ini sejalan dengan teori pengakuan yang dikemukakan oleh Axel Honneth yaitu cinta, hak-hak legal, dan solidaritas (Honneth dalam Lubis, 2015: 43-45). Cinta terkait dengan saling menerima dan mengakui satu sama lain. Hak-hak legal terkait dengan setiap subjek atau suami dan istri memiliki kedudukan yang sama. Solidaritas terkait dengan penerimaan identitas personal subjek. Kondisi tersebut diwujudkan dalam pengambilan keputusan dilakukan secara bersama dan setara antara laki-laki dan perempuan dalam melaksanakan pengelolaan usaha tani.

Peran penting perempuan juga ditunjukkan dari hasil penelitian Elizabeth (2008) pada Jurnal Iptek Tanaman Pangan bahwa "peran ganda wanita tani sangat strategis dalam peningkatan produktivitas usaha tani dan berpotensi untuk meningkatkan pendapatan dan ketahanan pangan menuju kesejahteraan rumah tangga petani di pedesaan" (Elizabeth, 2008: 67).

Partisipasi perempuan dalam usaha tani tersebut, menunjukkan adanya kesetaraan antara laki-laki dan perempuan. Kondisi tersebut sesuai dengan "konsep kemitraan terpadu yang tergambarkan dengan adanya perilaku saling menyesuaikan diri, saling pengertian, saling tenggang rasa, saling penghargaan, saling bertanggung jawab, saling gotong royong dan saling membantu antara suami dan istri, serta saling mengakui berhak atas perwujudan pribadi" (Munandar dan Utami dalam Pandu, 2006: 496). Kondisikondisi ini tergambar dari pernyataan informan. "Kemitraan terpadu yang dimaksudkan adalah bentuk kerjasama yang saling mengisi dan saling mendukung tanpa memperhitungkan besaran kontribusi dari masing-masing yang terlibat, tetapi lebih menekankan pada hasil dari kerjasama tersebut" (Pandu, 2006: 495-496).

Pandangan yang menyatakan bahwa peran perempuan hanya di rumah atau di sektor domestik (Tjokrowinoto, 2004:59) tidak berlaku bagi perempuan di Desa Goarie, Kecamatan Marioriwawo, Kabupaten Soppeng karena mereka ikut terlibat dan berpartisipasi dalam semua tahap kegiatan usaha tani. Mereka tidak hanya tinggal di rumah melaksanakan urusan rumah tangga tetapi ikut melaksanakan kegiatan produktif bersama suami atau dilakukan sendiri.

Pada saat tidak melaksanakan kegiatan usaha tani, perempuan juga berpartisipasi dalam kegiatan produktif untuk menambah pendapatan keluarga yaitu di bidang perkebunan dan peternakan. Di bidang perkebunan, perempuan ikut berkebun cengkeh, kopi, coklat, kemiri, dan gula aren. Di bidang peternakan, perempuan beternak ayam dan ikut memelihara sapi. Kondisi ini juga bertentangan dengan penjelasan Santoso (2011), bahwa "partisipasi perempuan pada umumnya merupakan perpanjangan tangan dari fungsi-fungsi domestik atau ranah privasi perempuan" (Santoso, 2011:212).

\section{SIMPULAN DAN SARAN \\ Simpulan}

Berdasarkan hasil penelitian yang telah dilakukan, maka dapat disimpulkan bahwa pada pengelolaan usaha tani di Desa Goarie, Kecamatan Marioriwawo, Kabupaten Soppeng perempuan ikut berpartisipasi pada semua tahap bersama laki-laki khususnya yanga menonjol pada tahap pembibitan, panen, pengolahan pasca panen, penjualan, 
penyimpanan hasil penjualan, dan pemanfaatan hasil penjualan. Upaya peningkatan kapasitas petani perempuan dan petani laki-laki penting untuk dilakukan melihat partisipasinya dalam pengelolaan usaha tani sekaligus mendorong tercapainya kesetaraan dan keadilan gender melalui pengarusutamaan gender (PUG).

\section{Saran}

Kepada pemerintah, untuk memberikan perhatian kepada perempuan dan laki-laki dalam rangka pengembangan kapasitas mereka dalam kegiatan usaha tani. Hal ini agar perempuan yang banyak terlibat dalam kegiatan usaha tani memiliki pengetahuan yang memadai dalam menjalankan aktivitasnya. Selain itu, memaksimalkan program kelompok tani dan penyuluh pertanian agar dapat berjalan sebagaimana mestinya sehingga dapat mendorong percepatan peningkatan kapasitas dari petani baik perempuan maupun laki-laki. Pemberian bantuan kepada petani tanpa disertai peningkatan kapasitas atau pemberdayaan tidak akan memberikan dampak yang signifikan pada peningkatan kesejahteraan petani.

Pelibatan perempuan dalam kegiatan kelompok tani (baik yang memiliki suami maupun yang tidak memiliki suami) atau pembentukan kelompok tani khusus perempuan agar mereka mendapatkan pengetahuan yang memadai dalam melaksanakan kegiatan usaha tani. Kegiatan usaha tani adalah kegitan bersama antara suami dan istri sehingga harus mendapat kesempatan yang sama untuk mendapatkan pengetahuan tentang bagaiman melaksanakan usaha tani yang baik sehingga dapat mendorong peningkatan hasil usaha tani.

\section{DAFTAR RUJUKAN}

Budiman, Arief. 1981. Pembagian Kerja secara Seksual, Sebuah Pembahasan Sosiologis tentang Peran Wanita di dalam Masyarakat. Jakarta: PT Gramedia.

Elizabeth, Roosganda. 2008. "Peran Ganda Wanita Tani dalam Mencapai Ketahanan Pangan Rumah Tangga di Pedesaan". Jurnal Iptek dan Tanaman Pangan 3 (1): 59-68.
Hutajulu, Josua P. 2015. "Analisis Peran Perempuan dalam Pertanian di Kecamatan Rasau Jaya Kabupaten Kuburaya”. Jurnal Social Economic of Agriculture 4 (1): 83-90.

Lubis, Akhyar Yusuf. 2015. Pemikiran Kritis Kontemporer. Jakarta: Rajawali Press.

Nugroho, Riant. 2011. Gender dan Strategi Pengarus-utamaannya di Indonesia. Yogyakarta: Pustaka Pelajar.

Pandu, Maria E. 2006. Gender di Tanah Mandar (Studi Kasus Kesetaraan dan Kemitraan Terpadu pada Komunitas Nelayan Mandar di Lingkungan Rangas Barat, Kelurahan Totoli, Kecamatan BanggaE, Kabupaten Majene). Makassar: Disertasi Program Pascasarjana Universitas Hasanuddin.

Santoso, Widjajanti M. 2011. Sosiologi Feminisme, Konstruksi Perempuan dalam Industri Media. Yogyakarta: LKIS.

Sugiyono. 2014. Metode Penelitian Kombinasi (Mixed Methods). Bandung: Alfabeta.

Sulaeman, Munandar M dan Siti Homzah, (ed). 2010. Kekerasan terhadap Perempuan Tinjauan dalam Berbagai Disiplin Ilmu \& Kasus Kekerasan. Bandung: Refika Aditama.

Tjokrowinoto, Moeljarto. 2004. Pembangunan Dilema dan Tantangan. Yogyakarta: Pustaka Pelajar.

\section{Editor In Chief}

\section{Rosmini Maru}

rosminimaru@unm.ac.id

\section{Publisher}

\section{Geography Education, Postgraduate Program, Universitas Negeri Makassar Jl. Bonto Langkasa Gunungsari Baru Makassar, 90222 Kampus PPs UNM Makassar Gedung AB ruang 01 , Indonesia Email : ugj@unm.ac.id}

\section{Info Berlangganan Jurnal 085299874629 / Ihsan}

